\title{
The Viscosity Effect of Masticated Natural vs. Synthetic Isoprene Rubber on Toughening of Polylactic Acid
}

\author{
Supanut Phattarateera (iD) and Cattaleeya Pattamaprom (D) \\ Department of Chemical Engineering, Thammasat School of Engineering, Thammasat University, Pathum Thani 12120, Thailand \\ Correspondence should be addressed to Cattaleeya Pattamaprom; cattalee@engr.tu.ac.th
}

Received 26 February 2019; Revised 2 May 2019; Accepted 12 May 2019; Published 27 May 2019

Academic Editor: Antonio Facchetti

Copyright ( 2019 Supanut Phattarateera and Cattaleeya Pattamaprom. This is an open access article distributed under the Creative Commons Attribution License, which permits unrestricted use, distribution, and reproduction in any medium, provided the original work is properly cited.

\begin{abstract}
This study investigated the different viscosity effects of natural isoprene rubber (NR) compared to the synthetic one (IR) on toughening of polylactic acid (PLA). Here, $15 \mathrm{wt} \%$ rubber was melt blended with PLA in an internal mixer at $180^{\circ} \mathrm{C}$ and $50 \mathrm{rpm}$. It was found that the addition of these rubbers led to a significant increase in the tensile toughness and impact strength. These rubbers were masticated at $50^{\circ} \mathrm{C}$ and at $200 \mathrm{rpm}$ for various mastication times to reduce their molecular weights. A too-long mastication time was found to adversely affect the impact strength and tensile toughness due to the fast agglomeration of rubber particles. At a comparable viscosity, it was remarkable that the impact strength of PLA/NR was higher than that of PLA/IR regardless of the similar chemical structures probably because the presence of nonrubber components including proteins and lipids could enhance the interfacial interaction between NR and the PLA matrix.
\end{abstract}

\section{Introduction}

Natural rubber (NR) from the Hevea brasiliensis tree is the only nonsynthetic rubber that has been in commercial use since the beginning of the 20th century. NR is practically pure poly(cis-1,4 isoprene) (containing more than $99.9 \%$ of cis-1.4 isoprene units) with a small amount of nonrubber components including proteins, lipids, and phospholipids [1]. The synthetic equivalent of natural rubber is the synthetic polyisoprene rubber (IR), which can be produced by the polymerization of 2-methyl-1,3-butadiene with the Ziegler-Natta catalyst [2]. Even though IR has the same building blocks as NR, it could not be synthesized as purely cis-1,4 polyisoprene. The commercial IR contained about 98\% cis-1,4 and approximately 2\% 3,4-isoprene units [3]. Their slight difference in isomeric forms led to differences in the crystallization characteristics and regularity of the molecular structure. Consequently, the mechanical properties such as modulus, tensile strength, tear resistance, and the building tack of IR are slightly inferior to that of NR [4]. Moreover, because IR used a catalyst to synthesize the equivalent chemical structure of NR, the price of IR is thus more expensive. Both NR and IR are often mixed with other ingredients such as oils, fillers, crosslinking agents, and antioxidants to obtain various elastomeric properties. Both NR and IR are excellent choices for dynamic applications at low and ambient temperatures with good fatigue resistance.

In the past, the use of NR to improve the toughness of PLA was of interest because NR has excellent elastic properties. Bitinis et al. [5] found that the optimal NR content to improve the toughness of PLA was $10 \mathrm{wt} \%$. Tensile tests of the samples showed a drastic increase in the average elongation at break from $5 \%$ to $200 \%$. Chuanhui et al. [6] found that the blend of PLA with $35 \mathrm{wt} \%$ NR had an impact strength of about $500 \mathrm{~J} / \mathrm{m}$, which was 7 times that of the neat PLA. Pattamaprom et al. [7] found that masticated NRs could improve the impact strength of the blends at lower NR contents than the unmasticated NR. For the use of IR in PLA, Sachiko et al. [8] found that the impact strength of PLA/IR blends at the IR content of $10 \%$ was about $50 \mathrm{~J} / \mathrm{m}$, which was 3 times higher than that of neat PLA. Phruksaphithak et al. [9] found that the elongations at break of PLA/NR and PLA/IR at $5 \mathrm{wt} \%$ 
rubber content were $29 \%$ and $18 \%$, respectively, compared to only $5 \%$ for neat PLA.

From the aforementioned literature, the toughening effect of NR and IR in PLA seems to depend on their viscosities, which is also directly relevant to their molecular weight. To investigate other effects beyond molecular weight, this current research systematically compared the effect of NR and IR at various rubber viscosities on the mechanical properties and phase morphology of PLA/rubber blends.

\section{Materials and Methods}

2.1. Materials. Polylactic acid (PLA 4043D, NatureWorks, USA) has a D-lactide content of $4.25 \%$ and an MFI of $3 \mathrm{~g} / 10 \mathrm{~min}\left(190^{\circ} \mathrm{C}, 2.16 \mathrm{~kg}\right)$. It was dried at $80^{\circ} \mathrm{C}$ for 8 hours in an oven before use. The grade of natural rubber (NR) was STR5L obtained from Srijareon Rubber Co. Ltd., Thailand. Polyisoprene (IR), grade IR2200, was obtained from Innovation Group Co. Ltd., Thailand.

\subsection{Sample Preparation}

2.2.1. Preparation of Masticated NR. NR and IR were masticated in an internal mixer (Brabender Plasticorder $350 \mathrm{E} 3 \mathrm{Z}$ ) by using a Banbury-type rotor. The mastication times were varied from 0 to 24 min to reduce the rubber's viscosity, where the initial chamber temperature was set at $50^{\circ} \mathrm{C}$ with a rotor speed of $200 \mathrm{rpm}$. After that, the masticated rubbers were cut into small pieces before blending with PLA. For code names, NR and IR masticated for $x$ minutes are called NRx and IRx, respectively, and the unmasticated IR is denoted as IR0. In addition, the compounds of PLA with NRx and those with IRx are called PLA/NRx and PLA/IRx, respectively.

2.2.2. PLA/Rubber Blend Preparation. The melt blending of PLA with a rubber was carried out in an internal mixer at $180^{\circ} \mathrm{C}$ with a rotor speed of $50 \mathrm{rpm}$. The ratio of PLA to rubber was fixed at $85: 15$ by weight. The mixing began by kneading PLA in the internal mixer for 2 minutes before adding the specified amount of rubber. The mixing was then continued for another 12 minutes.

2.3. The Thermal Analysis. The thermal properties of NR and IR were investigated by a METTLER TOLEDO (DSC 3) differential scanning calorimeter at a heating rate of $10^{\circ} \mathrm{C} / \mathrm{min}$ from -80 to $60^{\circ} \mathrm{C}$.

2.4. Rheological Test. The dynamic frequency sweep measurements of unmasticated and masticated rubbers (NR and IR) were performed in the linear viscoelastic regime using a Kinexus Pro rotational rheometer from Malvern Instruments. The measurements were carried out using a $25 \mathrm{~mm}$ diameter parallel plate fixture. Dynamic storage modulus $\left(G^{\prime}\right)$, dynamic loss modulus $\left(G^{\prime \prime}\right)$, and complex viscosity $\left(\eta^{*}\right)$ were recorded as functions of angular frequency $(\omega)$ at $180^{\circ} \mathrm{C}$. The frequency test was fixed at $1 \%$ strain amplitude to ensure that all measurements were taken within the linear viscoelastic limit.

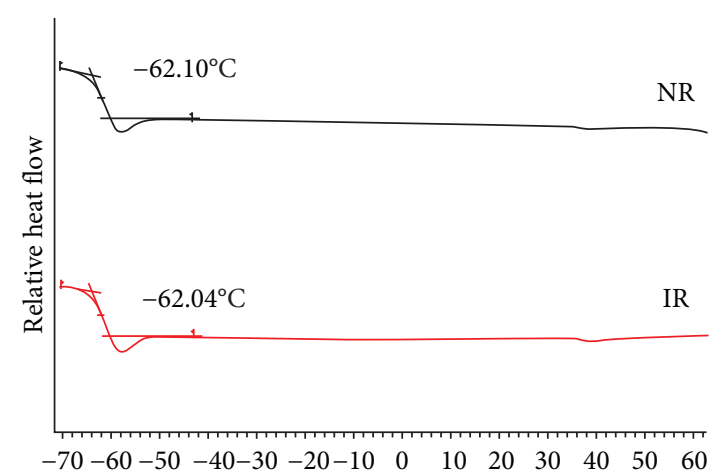

FIgURE 1: DSC thermograms showing the glass transition temperatures of NR and IR.

2.5. Characterization by Fourier-Transform Infrared Spectroscopy (FT-IR). FT-IR spectra were recorded with the OPUS 7.0 software on a Bruker Tensor 27 spectrometer, using the Attenuated Total Reflection (ATR) mode, in the range of $3600-600 \mathrm{~cm}^{-1}$ with a resolution of $2 \mathrm{~cm}^{-1}$.

2.6. Mechanical Properties. Tensile tests were performed according to ASTM D638 type I on an Instron machine Model 5969, Instron Engineering Corporation, USA, at $25^{\circ} \mathrm{C}$, with a cross-head speed of $5 \mathrm{~mm} / \mathrm{min}$. Dumbbellshaped specimens were prepared from the sheet obtained by compression molding at a pressure of $1500 \mathrm{psi}$ at $190^{\circ} \mathrm{C}$. At least five specimens of each sample were tested to determine the mean value and the standard deviation of the results. The notched Izod impact tests were measured according to ASTM D256 by the Rasil impactor using a pendulum energy of $2.7 \mathrm{~J}$ at $25^{\circ} \mathrm{C}$. For this measurement, the samples were cut, notched, and kept in desiccators overnight before the tests.

2.7. Morphology of the Blends by Scanning Electronic Microscope (SEM). The size and dispersion of rubber phases in the PLA matrices were observed on the freeze-fractured surfaces of the samples using a SEM (Camtrad, JEOL MX2000 operated at $15 \mathrm{keV}$ ). The impact-fractured surfaces of selected samples were also observed by a SEM to investigate the fracture behavior of the blends. All samples were coated with gold before the SEM analysis.

\section{Results and Discussion}

3.1. Characteristics of NR and IR. The glass transition temperatures $\left(T_{g}\right)$ of NR and IR are shown in Figure 1. It was found that the $T_{g}$ of NR and IR were not significantly different at about $-62^{\circ} \mathrm{C}$. The FT-IR spectra of natural and synthetic isoprene rubbers are compared in Figure 2. As can be seen, the FT-IR spectra of NR and IR showed the hydrocarbon fingerprints of polyisoprene with slight differences in some peaks. The $840 \mathrm{~cm}^{-1}$ band of the NR spectrum was attributed to the $\mathrm{C}-\mathrm{H}$ out-of-plane bending of the cis-1,4 additions, whereas this band was slightly shifted to $836 \mathrm{~cm}^{-1}$ for IR. The peak at $1016 \mathrm{~cm}^{-1}$ of IR was the stretching vibration of $\mathrm{C}-\mathrm{C}$ bond. The slightly higher intensity of this peak in 


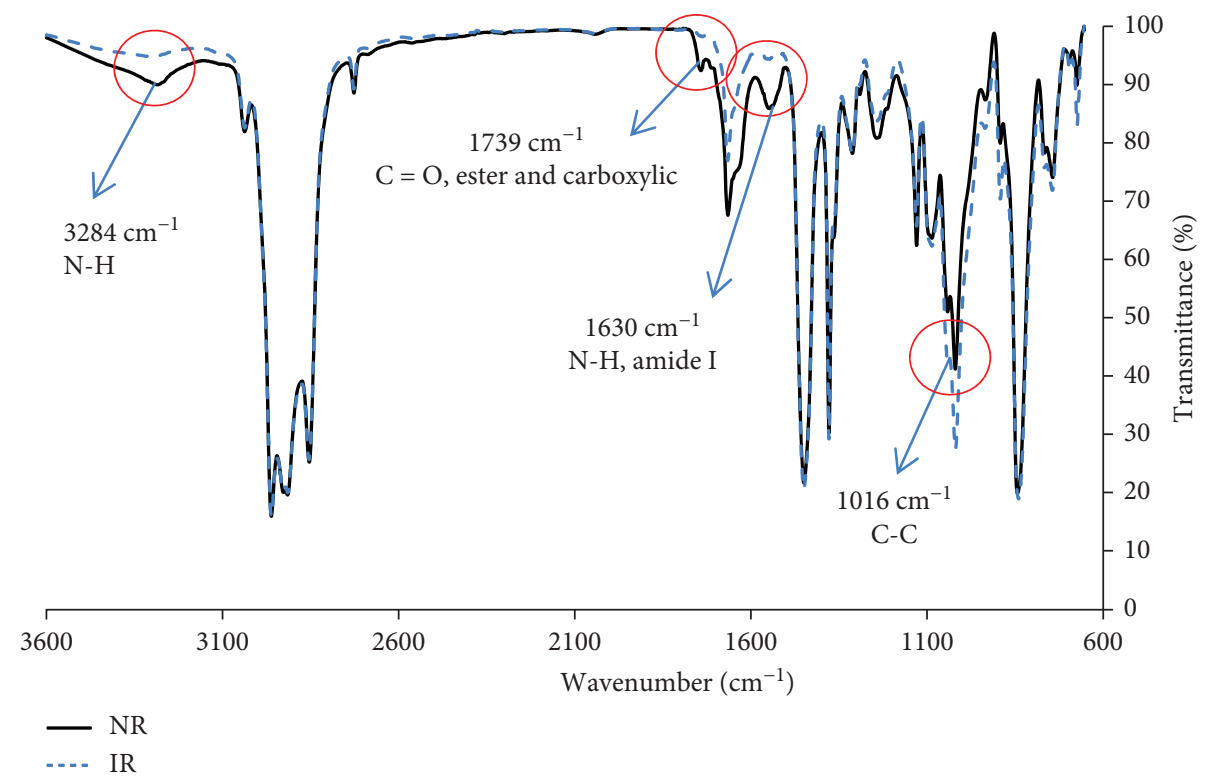

FIgURE 2: FT-IR spectra of NR and IR.

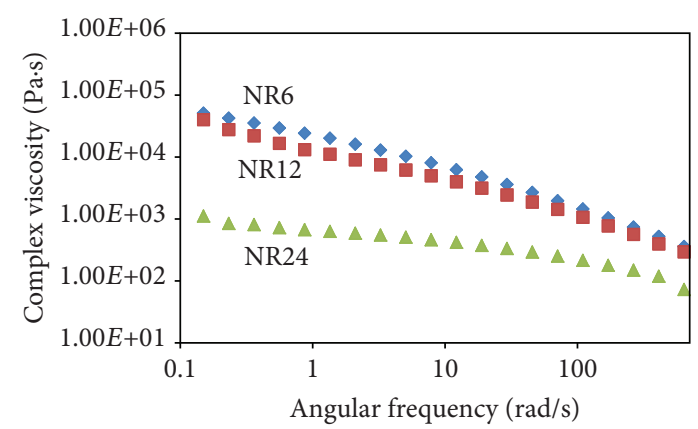

FIGURE 3: Complex viscosity of NR with the mastication times of 6, 12 , and 24 minutes denoted by NR6, NR12, and NR24, respectively.

IR indicated the presence of the 3,4-isoprene isomer [10]. On the other hand, the NR spectrum indicated the presence of many polar nonrubber components. These bands included an amine $(\mathrm{N}-\mathrm{H})$ stretching $\left(3284 \mathrm{~cm}^{-1}\right)$, an ester $(\mathrm{C}=\mathrm{O})$ stretching $\left(1739 \mathrm{~cm}^{-1}\right)$, and an amide I stretching $\left(1630 \mathrm{~cm}^{-1}\right)$. The amide I band was specific to peptide bonds and was linked to the presence of proteins in NR. On the other hand, ester, carboxyl, and carbonyl groups indicated the presence of lipids in NR.

3.2. Mastication of NR and IR. The rheological properties of various masticated NRs and IRs were compared in terms of the complex viscosity $\left(\eta^{*}\right)$ as a function of angular frequency $(\omega)$ in Figures 3 and 4, respectively. It was found that the $\eta^{*}$ of NR masticated for 12 minutes (NR12) decreased only slightly from that of NR masticated for 6 minutes (NR6). However, when increasing the mastication time to 24 minutes (NR24), the $\eta^{*}$ dropped significantly. This could be explained by the plastograph plotted between torque and

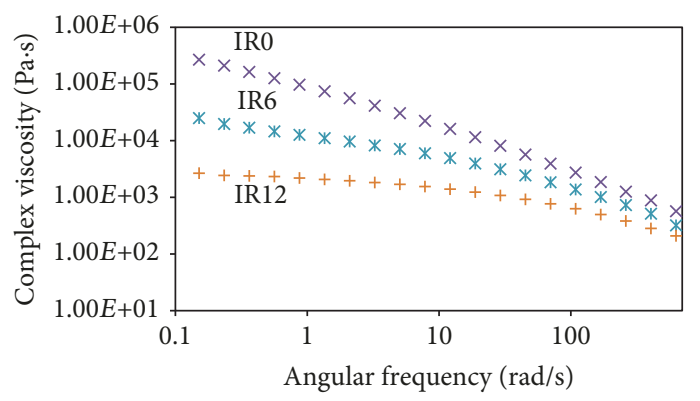

FIGURe 4: Complex viscosity of IR with the mastication times of 0,6 , and 12 minutes denoted by IR0, IR6, and IR12, respectively.

temperature during mastication in Figure 5, which indicated that the temperature of NR6 rose to a maximum of $180^{\circ} \mathrm{C}$. At longer mastication times, the mastication temperature of NR decreased due to lower viscosities indicating that the chain scission mechanism at this stage was shifted from shearing action toward thermooxidative degradation. The insignificant decrease in viscosity of NR12 from NR6 could be explained by the ineffective chain scission in the transition zone [11]. In addition, Pattamaprom et al. [7] reported the $\eta^{*}$ of NR0, which was the highest viscosity $\left(3 \times 10^{5} \mathrm{~Pa} \cdot \mathrm{s}\right)$. On the other hand, the temperature of masticated IRs rose to a stable temperature of $140^{\circ} \mathrm{C}$ indicating that the chain scission of IR occurred by both shearing action and thermal degradation throughout the mastication process [12].

3.3. The Effect of Mastication Time on the Impact Strength of PLA/NR and PLA/IR Blends. The impact strengths of PLA blended with unmasticated and masticated NRs and IRs at different mastication times are shown in Figure 6, and their stress-strain curves are illustrated in Figures 7 and 8, 


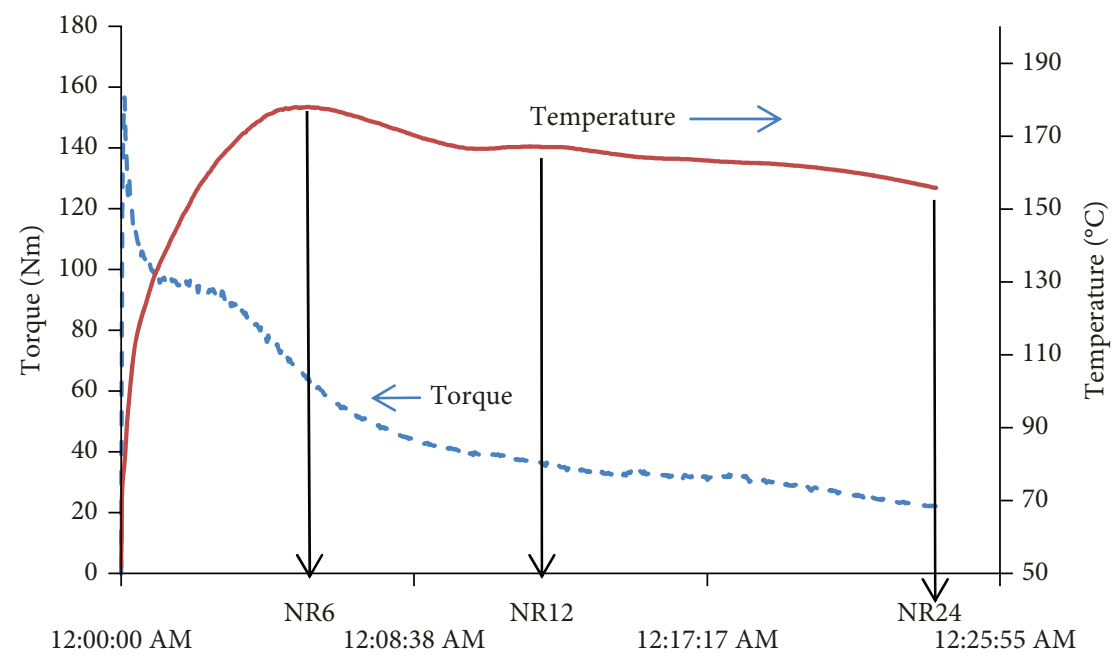

Time (HH:MM:SS)

(a)

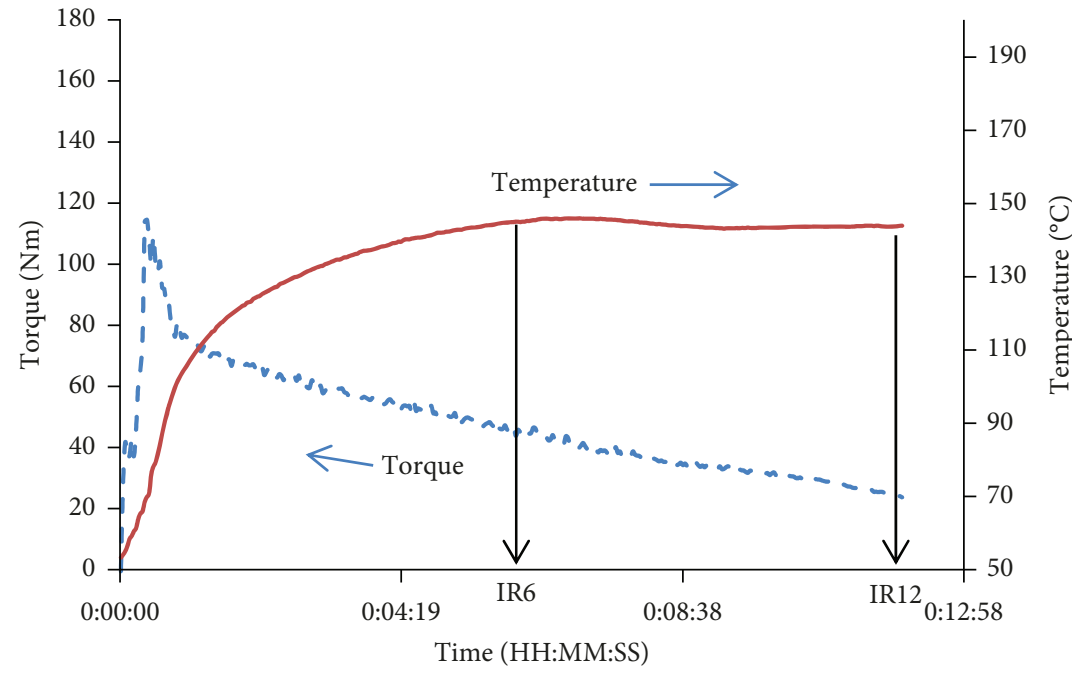

(b)

FIGURE 5: The plastograph of masticated NR and IR.

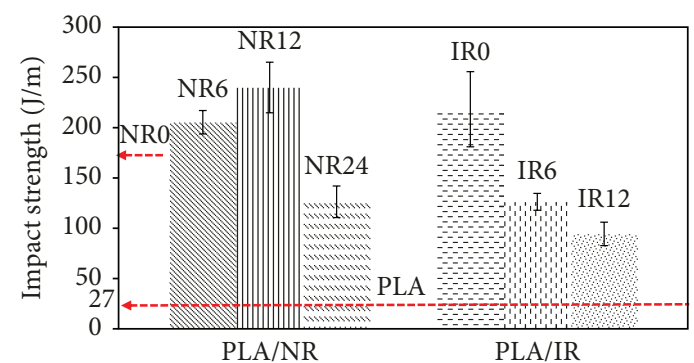

Figure 6: The impact strength of PLA/rubber blends.

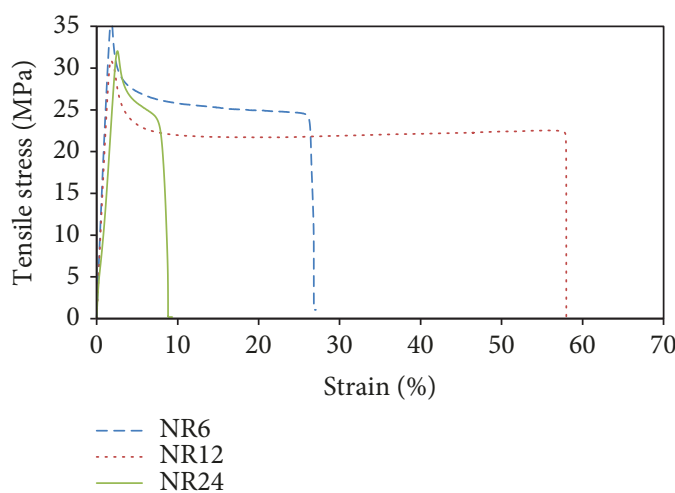

FIGURE 7: Stress-strain curves of PLA/NR with various mastication times. respectively. As can be seen, the masticated rubbers could impart at least a higher impact strength of $93 \mathrm{~J} / \mathrm{m}$ than the neat PLA and their toughness was also reflected by incomplete fractures of specimens after impact (Figure 9). For 


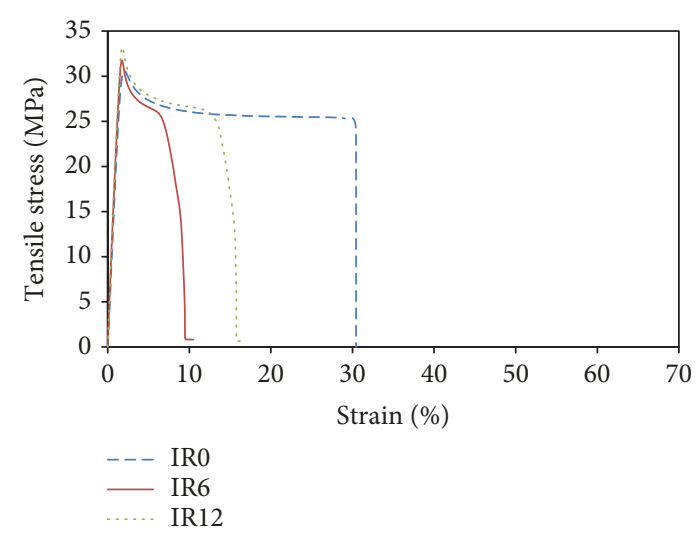

FIGURE 8: Stress-strain curves of PLA/IR with various mastication times.

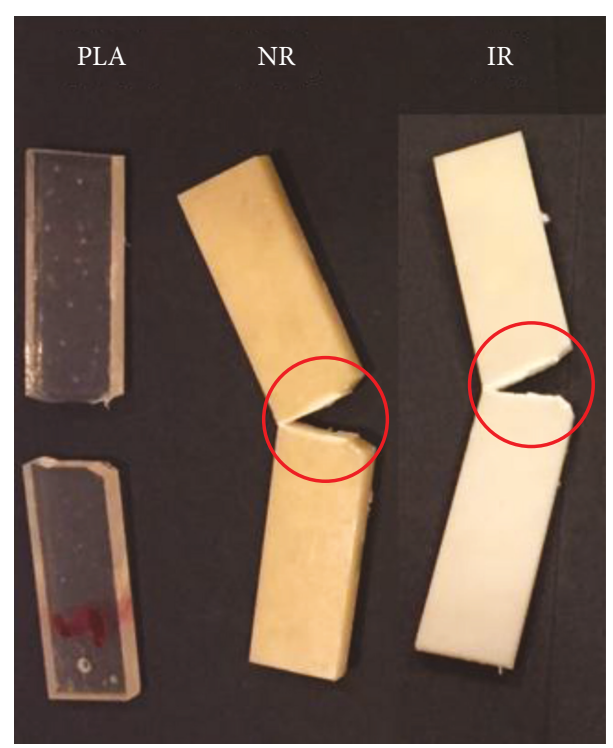

FIGURE 9: The fractured specimens after the notched Izod impact tests.

NR, Pattamaprom et al. reported in 2016 that the unmasticated NR (PLA/NR0) has an impact strength of about $175 \mathrm{~J} / \mathrm{m}$ with high viscosity and the decreased viscosity of masticated NR led to an improvement in impact strength and \% elongation at break of PLA/NR blends [7]. However, a too-long mastication time $(24 \mathrm{~min})$ led to a significant decrease in viscosity and to a dramatic decrease in both the impact strength and the \% elongation at break. The changes in the impact strength and the \% elongation at break could be explained by their SEM micrographs in Figure 10. As can be seen, an appropriate mastication time (12 $\mathrm{min})$, which led to the highest impact strength, provided a smaller average rubber size in the freeze-fracture micrograph due to the lower molecular weight and viscosity. Moreover, a lot of fibrillation observed in the impact-fractured surface indicated the toughening mechanism by shear yielding. Nevertheless, at a toolong mastication time $(24 \mathrm{~min})$, the average rubber size of
PLA/NR24 was larger due to the higher degree of shearinduced agglomeration of low-viscosity rubber. This led to only a small amount of fibrillation in the impact-fractured surface due to a too-low entanglement network, and this could explain the lowest impact strength of PLA/NR24.

For the case of IR, the effect of mastication time was different. The impact strength and elongation at break of PLA/IR successively decreased with mastication time as shown in Figures 6 and 8. It was found that the impact strength and elongation at break of PLA/IR decreased with longer mastication times, where PLA/IR0 had the highest impact strength $(218.2 \mathrm{~J} / \mathrm{m})$ and tensile elongation (30\%). The decrease in impact strength and elongation at break could be explained by the SEM micrographs (Figure 11). As can be seen, IR with a longer mastication time indicated a larger rubber size and the lower-viscosity rubber led to faster shear-induced agglomeration of rubber particles. The SEM micrographs after impact fracture also indicated a smaller amount of fibrillation when masticating at longer times.

Note that the improvement in the mechanical properties of PLA/NR blends when NR was masticated was proposed by Zhang et al. in 2013 to be due to more carbonyl or hydroxyl groups generated after mastication of NR [13]. However, our FT-IR results in Figure 12 indicated that NR inherently possesses carbonyl/carboxyl groups but the amounts of these groups barely change with mastication. In a similar way, the carbonyl/carboxyl peaks were not present in the FT-IR spectrum of unmasticated IR nor did it occur after mastication. This ruled out the effect of increased PLA/rubber interaction after mastication and confirmed that the changes in the mechanical properties of PLA/masticated rubber blends for the same rubber depended mainly on the rubber viscosity.

3.4. The Comparison of PLA/NR and PLA/IR Blends at the Same Viscosity. The impact strengths of PLA/NR and PLA/IR are plotted as a function of complex viscosity $\left(\eta^{*}\right)$ at an angular frequency of $0.1 \mathrm{~Hz}$ in Figure 13. The effect of viscosity was excluded by comparing the specimens at the same $\eta^{*}$. Here, IR6 possessed a comparable viscosity to NR12; however, the rubber domain size of NR12 was found to be smaller with a narrower size distribution $(2.09 \pm 0.36 \mu \mathrm{m})$ than that of IR6 $(2.23 \pm 0.46)$. Moreover, PLA/NR12 possessed an outstandingly higher impact strength with a much higher elongation at break than PLA/IR6, regardless of their comparable $\eta^{*}$ and similar chemical structures. It was probably because the nonrubber components, including lipid and protein molecules, could improve the interfacial interaction between the PLA matrix and NR domains as shown by a smoother phase boundary of PLA/NR (Figure 14). The specimen after the impact test also showed a higher degree of fibrillation indicating better energy absorption with the localized plastic deformation of PLA/NR. The effects of \%crystallinity of the blends to the impact strength were disregarded as all samples possessed $\%$ crystallinity lower than $5 \%$. This was apparent in our previous work [7], where there was no correlation between the $\%$ crystallinity and the impact toughness for blends with low \%crystallinity. 
PLA/NR6

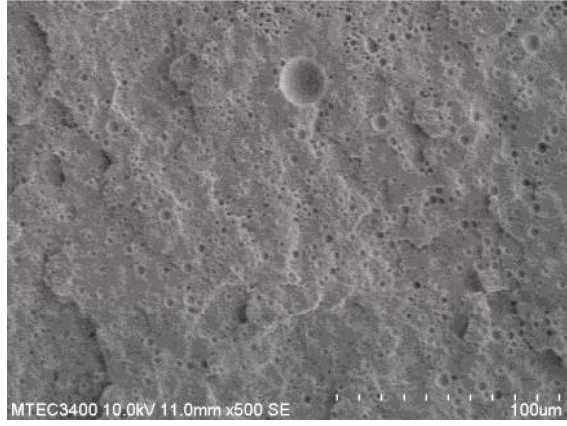

PLA/NR6

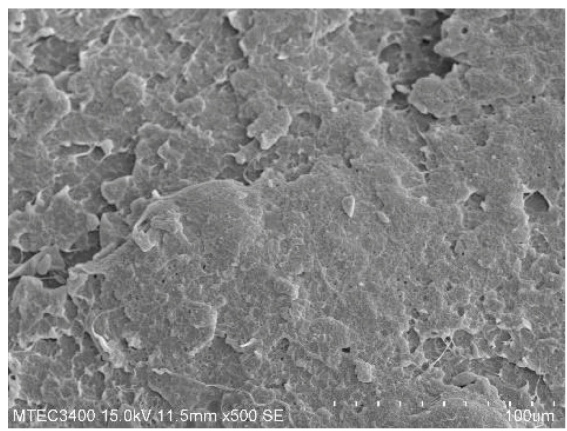

PLA/NR12

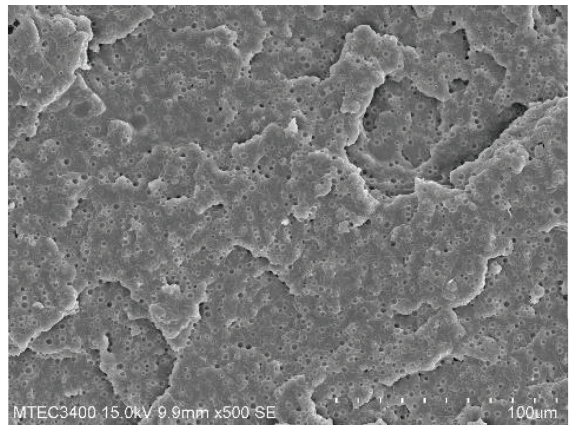

(a) Freeze-fractured surfaces

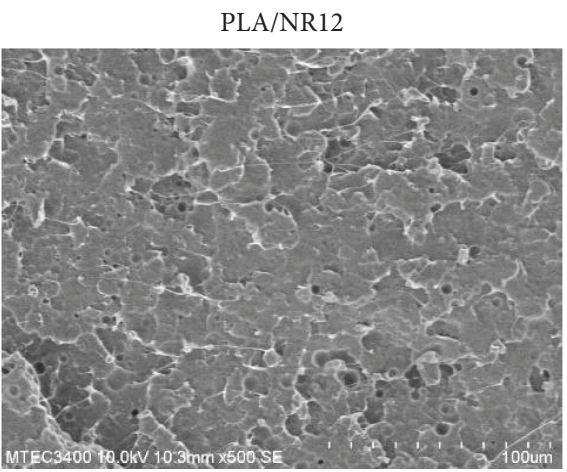

(b) Impact-fractured surfaces
PLA/NR24

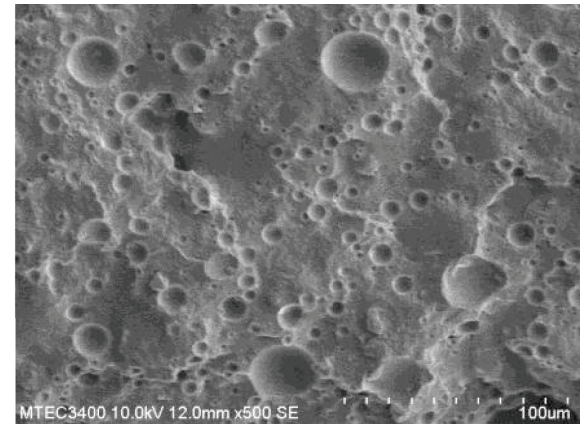

PLA/NR24

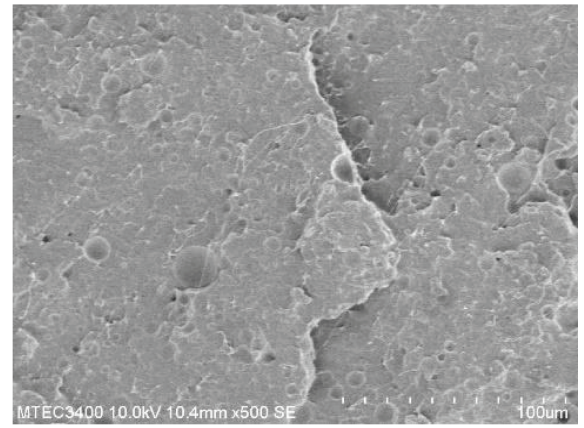

FIGURE 10: SEM micrographs at 500x of PLA/NR blends using NR masticated for different mastication times.

PLA/IR0

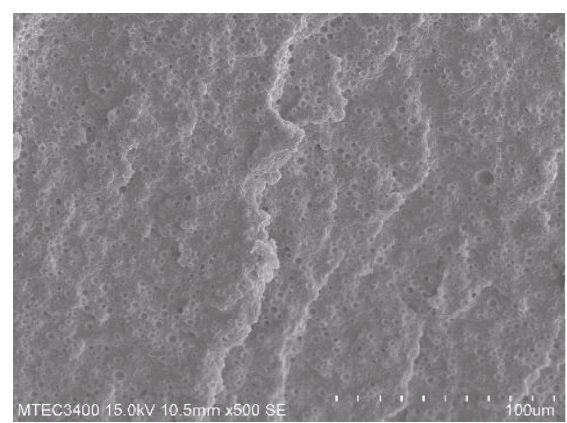

PLA/IR0

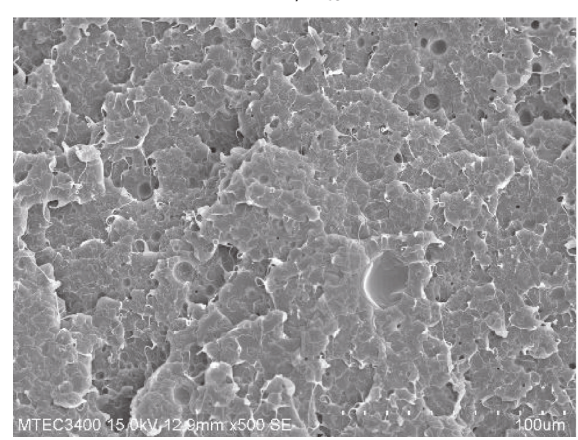

PLA/IR6

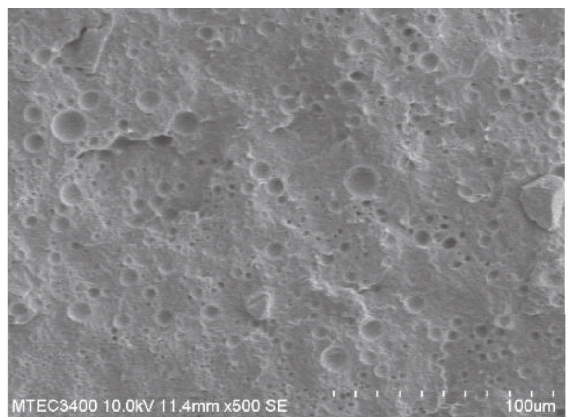

(a) Freeze-fractured surfaces

PLA/IR6

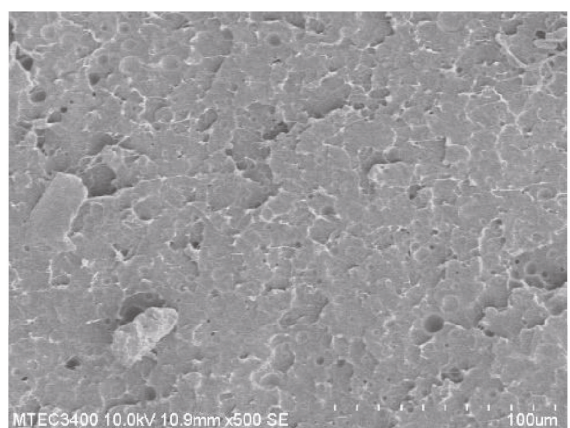

(b) Impact-fractured surfaces
PLA/IR12

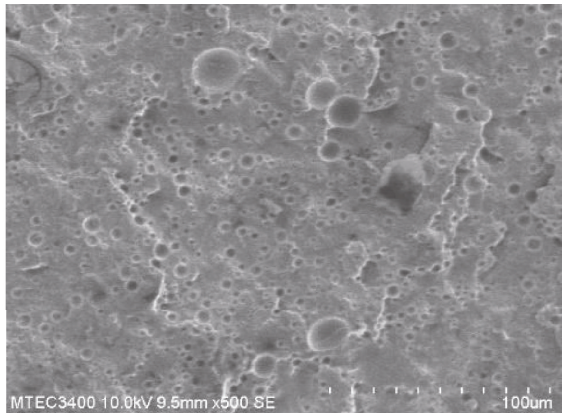

PLA/IR12

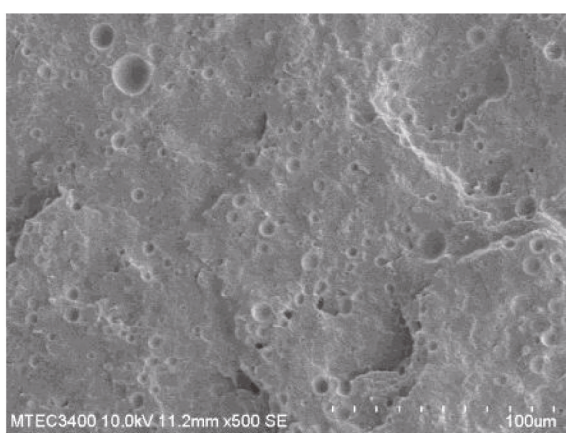

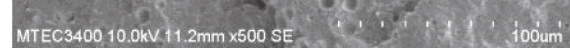

FIGURE 11: SEM micrographs at 500x of PLA/IR blends using IR masticated for different mastication times. 


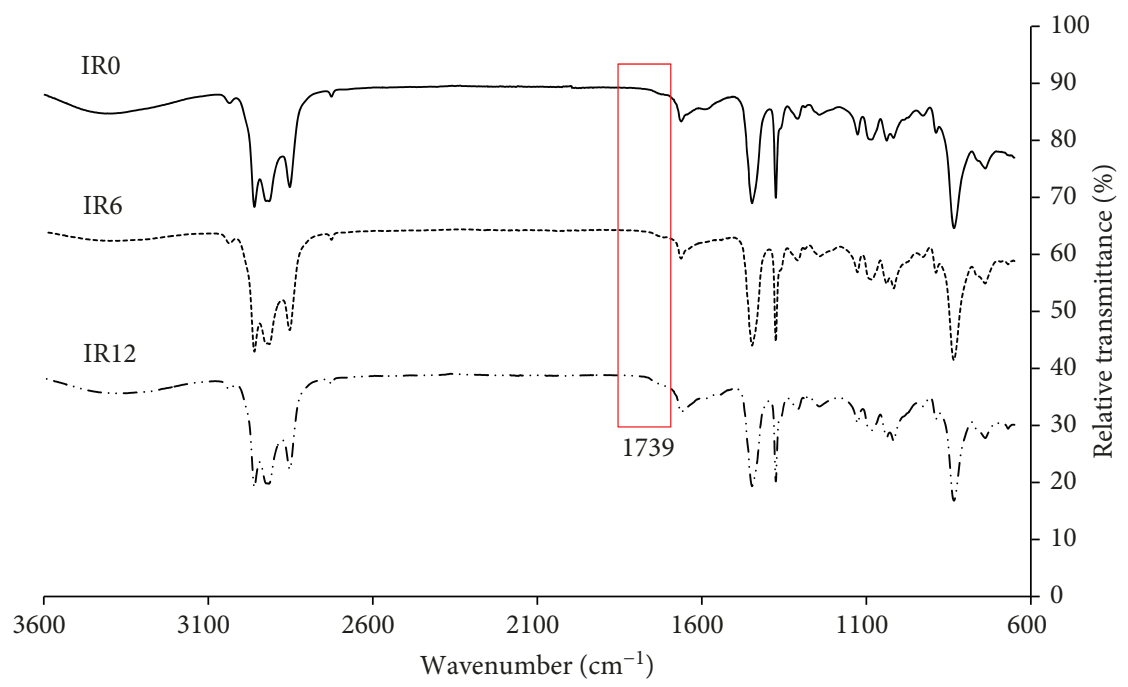

(a)

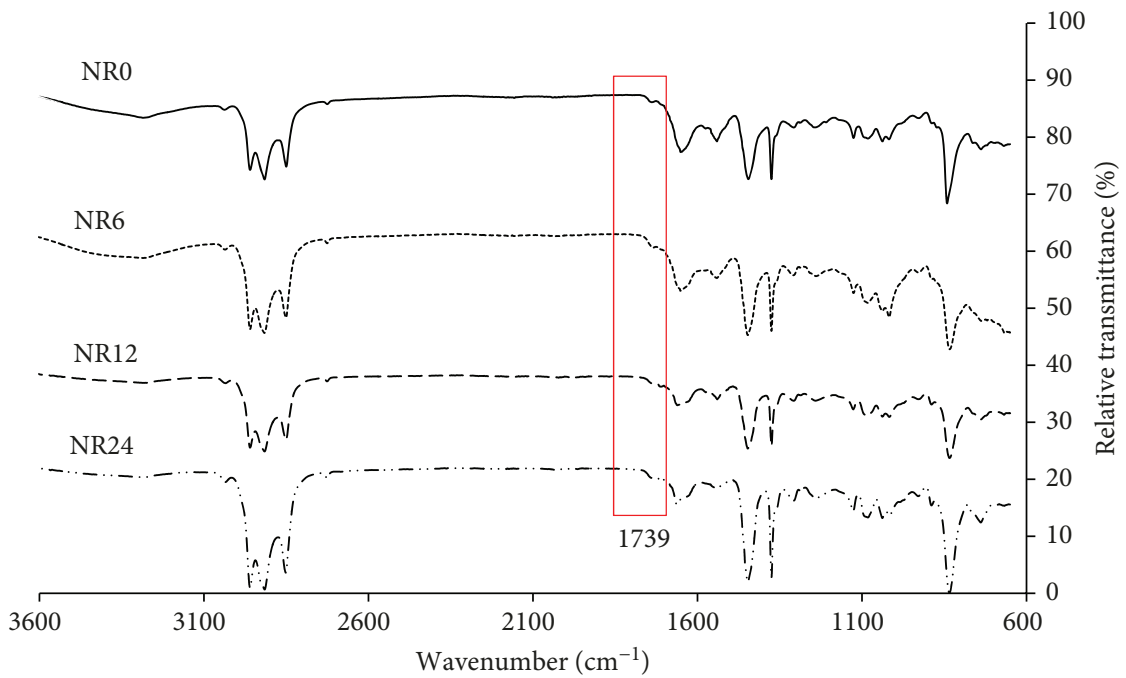

(b)

FIgURE 12: FT-IR spectra of (a) IR masticated for 0, 6, and 12 minutes and (b) NR masticated for 0, 6, 12, and 24 minutes.

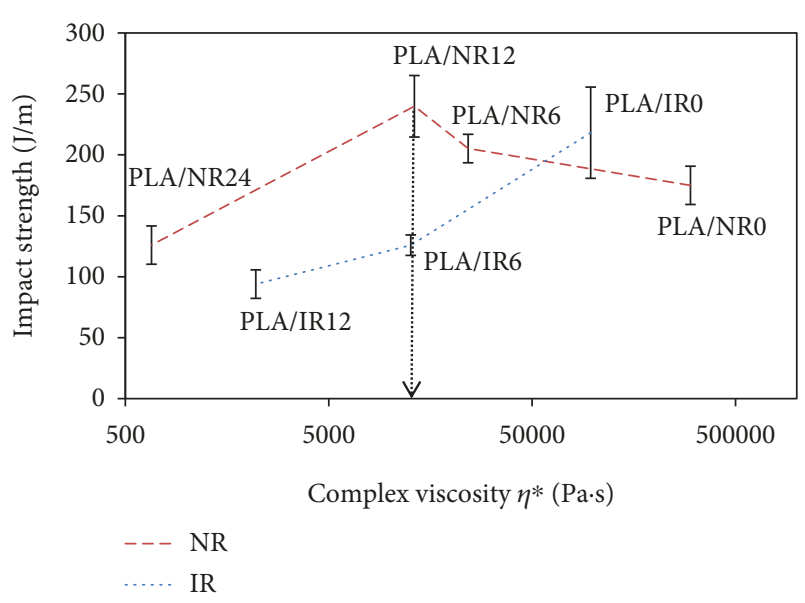

FIGURE 13: Complex viscosities of NR and IR with various mastication times versus impact strength at $0.1 \mathrm{~Hz}$.

\section{Conclusion}

The brittleness of PLA could be lessened by blending with NR or IR. The addition of $15 \mathrm{wt} \%$ of NR or IR led to an approximately 10 times increase of impact strength and a 20 -fold increase in \% elongation from that of neat PLA. It was found that the mastication time affected the viscosity, impact strength, and tensile toughness of the blends. In the case of NR, the optimal NR viscosity was $4.03 \times 10^{4} \mathrm{~Pa} \cdot \mathrm{s}$ (at $0.1 \mathrm{~Hz}, 180^{\circ} \mathrm{C}$ ), which was achieved by masticating for $12 \mathrm{~min}$. However, a too-long mastication time $(24 \mathrm{~min})$ led to a dramatic decrease in both the impact strength and the $\%$ elongation at break due to fast shear-induced agglomeration of the low-viscosity rubber. For IR, the impact strength and elongation at break of PLA/IR successively decreased with mastication time, where the optimal IR viscosity was that of the unmasticated IR $\left(2.68 \times 10^{5} \mathrm{~Pa} \cdot \mathrm{s}\right.$ at $0.1 \mathrm{~Hz}$, $\left.180^{\circ} \mathrm{C}\right)$. When comparing NR and IR at similar viscosities (NR12 and IR6), it was found that the impact strength and 


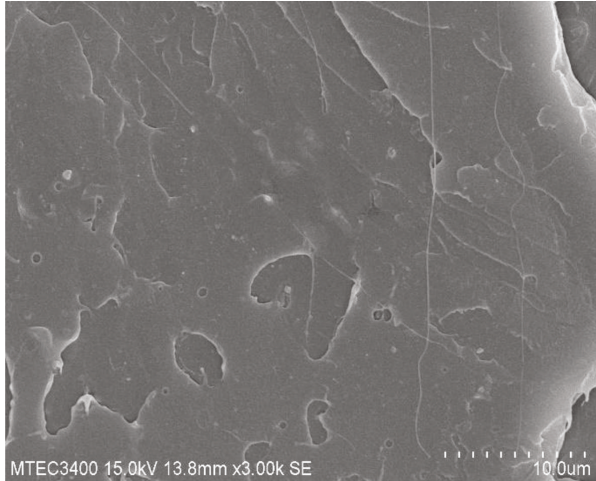

(a) Freeze-fractured surface of PLA

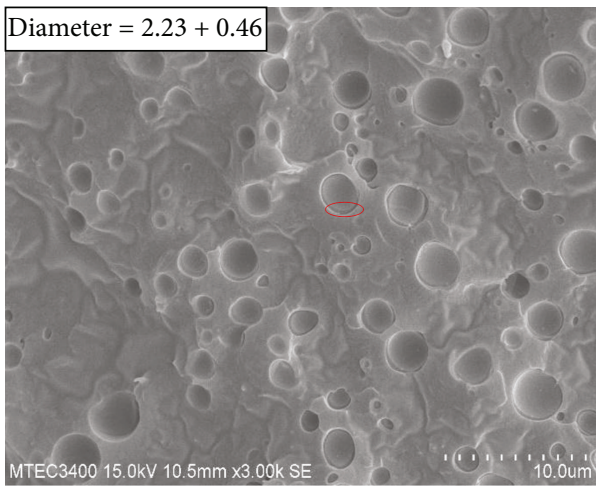

(c) Freeze-fractured surface of PLA/IR6

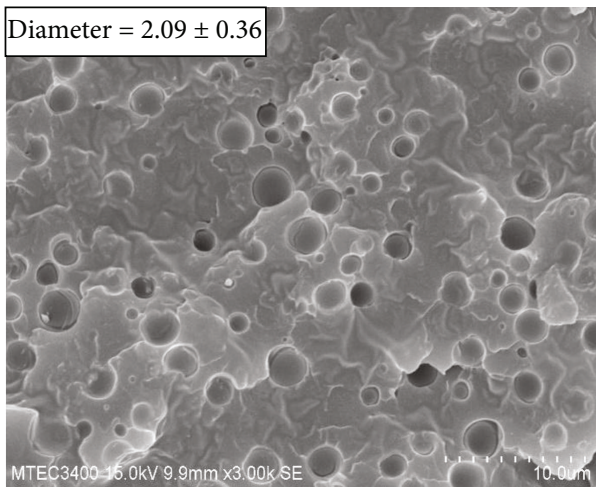

(e) Freeze-fractured surface of PLA/NR12

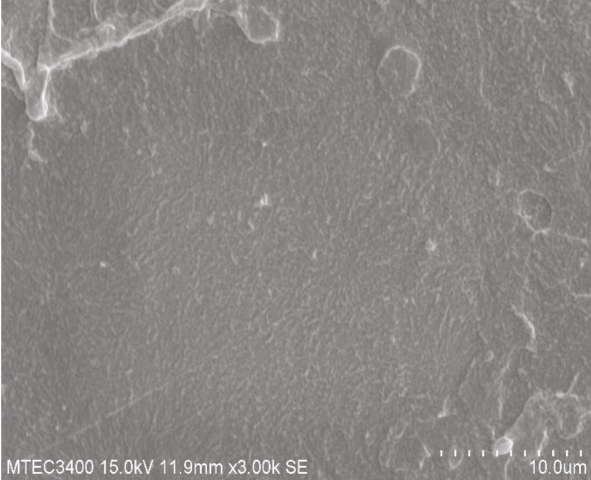

(b) PLA after impact test

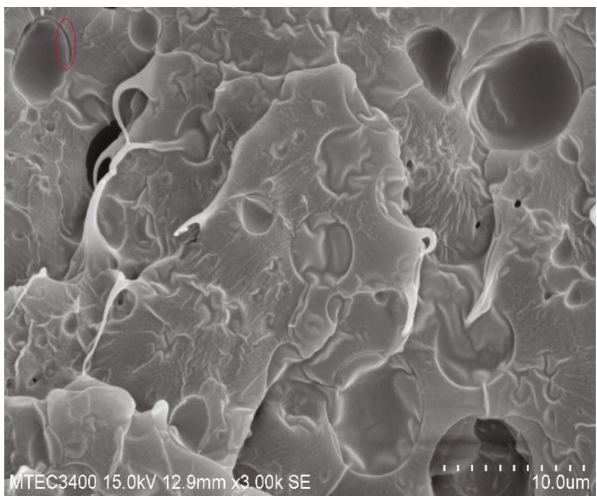

(d) PLA/IR6 after impact test

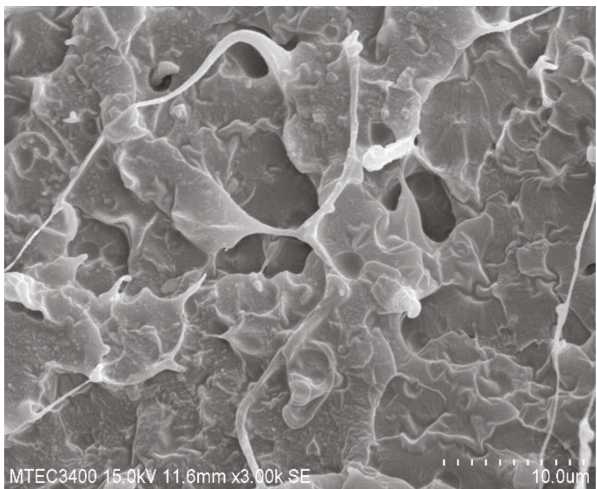

(f) PLA/NR12 after impact test

FIGURE 14: SEM micrographs of the freeze-fractured and impact-fractured surfaces of PLA and the blends of PLA/rubber at 3000x.

$\%$ elongation at break of PLA/NR12 were higher than those of PLA/IR6, regardless of similar chemical structures. It was probably because the nonrubber components could enhance the interfacial interaction between NR and the PLA matrix and provided smaller rubber domain sizes.

\section{Data Availability}

The data used to support the findings of this study are available from the corresponding author upon request.

\section{Conflicts of Interest}

The authors declare that they have no conflicts of interest.

\section{Acknowledgments}

The authors acknowledge receiving financial support from the Department of Chemical Engineering, Thammasat University and the National Metal and Materials Technology Center (MTEC).

\section{References}

[1] M. W. Laurence, Elastomers and Rubbers. Permeability Properties of Plastics and Elastomers, Elsevier, Third edition, 2012.

[2] P. A. Ciullo and N. Hewitt, "Compounding materials," in The Rubber Formulary, pp. 4-49, 1999. 
[3] "Polymerdatabase. Retrieved from polymerdatabase," June 2018, http://polymerdatabase.com/Elastomers/Isoprene.html.

[4] K. Hanhi, M. Poikelispää, and H.-M. Tirilä, "Elastomeric materials," July 2018, http://laroverket.com/wp-content/ uploads/2015/03/Elastomeric_materials.pdf.

[5] N. Bitinis, R. Verdejo, P. Cassagnau, and M. Lopez-Manchado, "Structure and properties of polylactide/natural rubber blends," Materials Chemistry and Physics, vol. 129, no. 3, pp. 823-831, 2011.

[6] C. Xu, D. Yuan, L. Fu, and Y. Chen, "Physical blend of PLA/NR with co-continuous phase structure: preparation, rheology property, mechanical properties and morphology," Polymer Testing, vol. 37, pp. 94-101, 2014.

[7] C. Pattamaprom, W. Chareonsalung, C. Teerawattananon, S. Ausopron, P. Prachayawasin, and P. Puyvelde, "Improvement in impact resistance of polylactic acid by masticated and compatibilized natural rubber," Iranian Polymer Journal, vol. 25, no. 2, pp. 169-178, 2016.

[8] I. Sachiko, N. Reiko, C. Keisuke, D. Tungalag, and I. Yoshio, "Toughening of poly(L-lactide) by melt blending with rubbers," Journal of Applied Polymer Science, vol. 113, pp. 558-566, 2009.

[9] N. Phruksaphithak and C. Noomhorm, "Polylactic acid/impact modifier blends," Advanced Materials Research, vol. 486, pp. 406-411, 2012.

[10] D. Chen, H. Shao, W. Yao, and B. Huang, "Fourier transform infrared spectral analysis of polyisoprene of a different microstructure," International Journal of Polymer Science, vol. 2013, Article ID 937284, 5 pages, 2013.

[11] C. Pattamaprom and N. Saengklin, "The rheological properties of masticated natural rubbers and their linear viscoelastic predictions," Rheologica Acta, vol. 55, no. 8, pp. 641-648, 2016.

[12] L. Mullins and W. F. Watson, "Mastication. IX. Sheardependence of degradation on hot mastication," Journal of Applied Polymer Science, vol. 1, no. 2, pp. 245-249, 1959.

[13] C. Zhang, Y. Huang, and C. Luo, "Enhanced ductility of polylactide materials: reactive blending with pre-hot sheared natural rubber," Journal of Polymer Research, vol. 20, no. 4, pp. 121-130, 2013. 


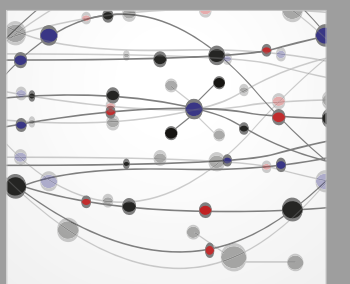

The Scientific World Journal
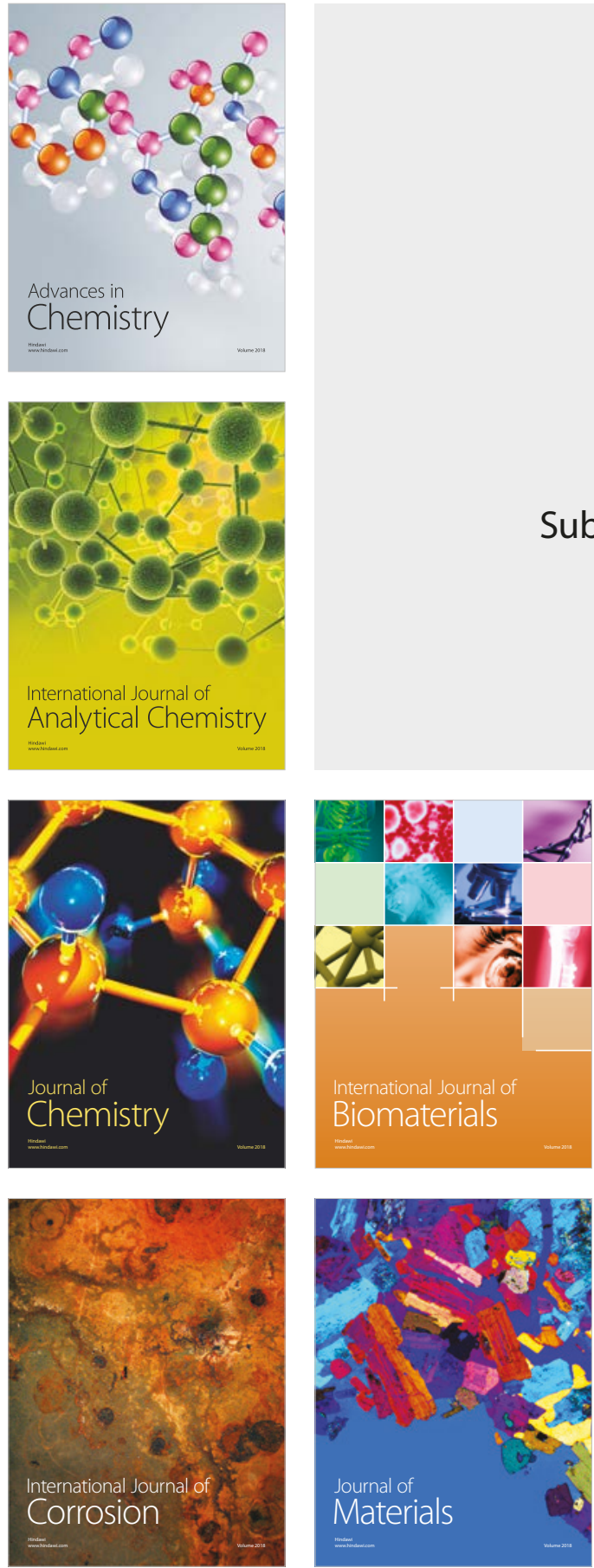

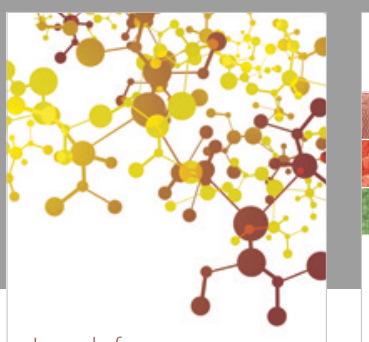

Journal of

Applied Chemistry
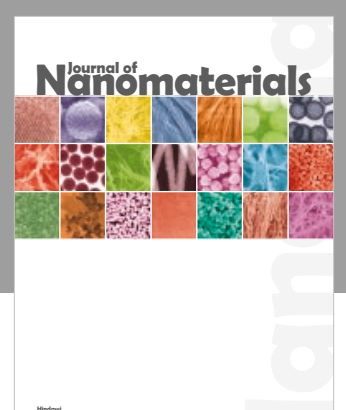

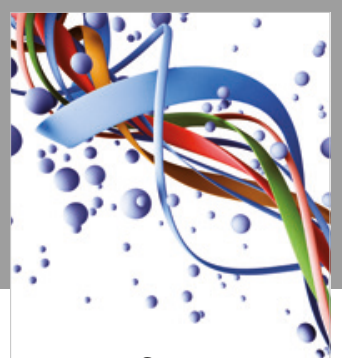

Scientifica

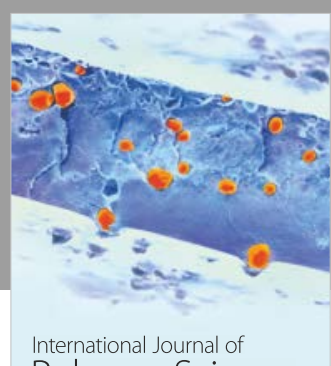

Polymer Science

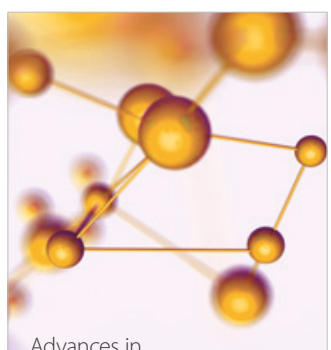

Physical Chemistry
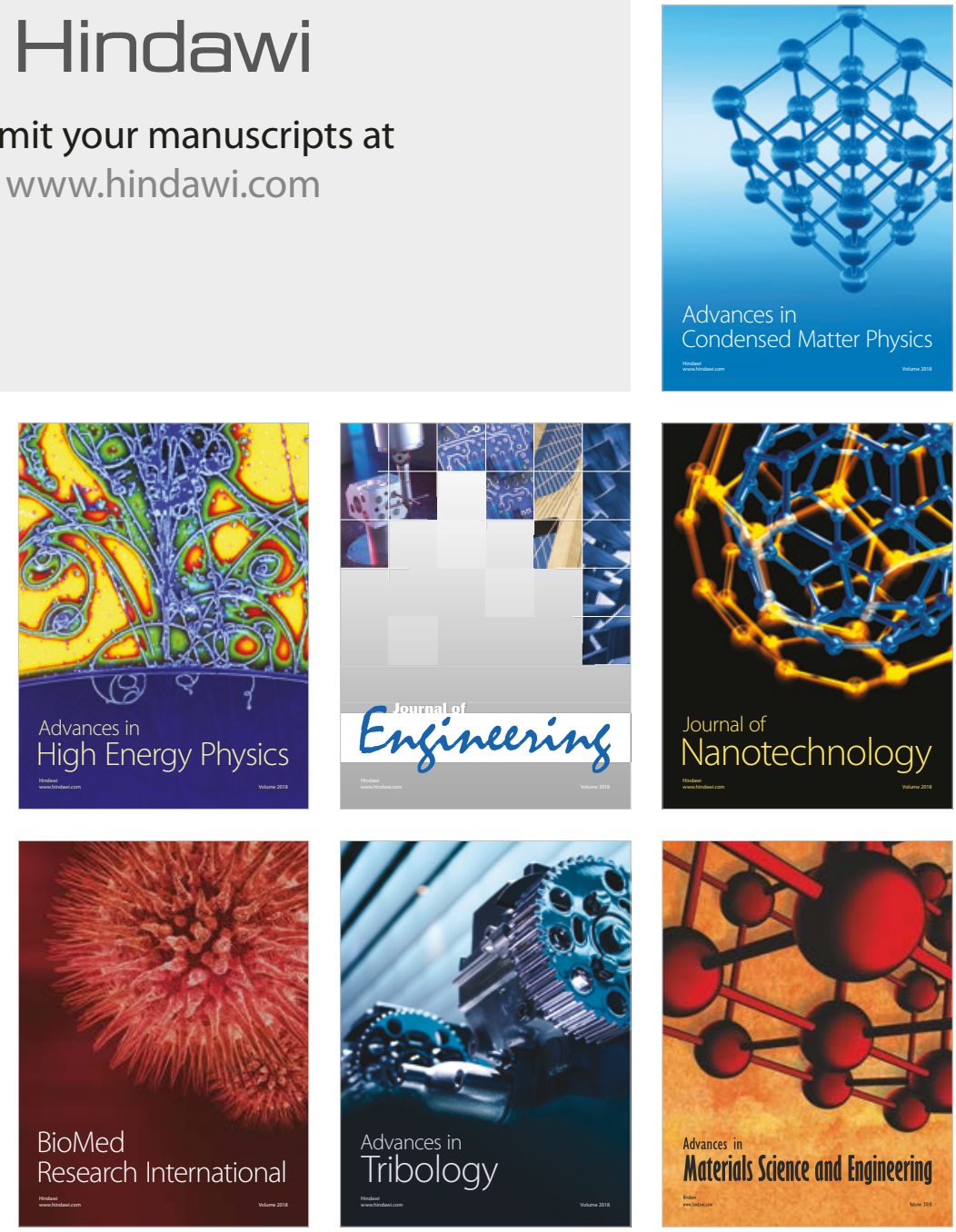